\title{
Partial Lipodystrophy
}

National Cancer Institute

\section{Source}

National Cancer Institute. Partial Lipodystrophy. NCI Thesaurus. Code C131296.

Loss and redistribution of subcutaneous and/or visceral adipose tissue from specific regions of the body. 